УДК 903.2:391(470.51)(045)

https://doi.org/10.24852/2587-6112.2021.2.314.324

\title{
ПРЕДМЕТЫ КОЛЬЧУЖНОГО ПЛЕТЕНИЯ В ЖЕНСКОМ УБОРЕ НАСЕЛЕНИЯ СРЕДНЕГО ПРИКАМЬЯ III-V ВВ.
}

\section{(C) 2021 г. О.Ф. Хайруллина}

Статья посвящена анализу малоизученной категории женского погребального инвентаря в могильниках мазунинского типа чегандинской культуры пьяноборской культурно-исторической общности (или мазунинской культуры, по Т.И. Останиной) - предметам кольчужного плетения. Данные изделия являются примером вторичного использования и творческого переосмысления элементов защитной экипировки воинов - кольчужных доспехов lorica hamata. Обнаружены в 97 погребальных комплексах, происходящих из 12 мазунинских могильников. Антропологические данные и сопутствующий погребальный инвентарь свидетельствуют об использовании данной категории вещей исключительно женским полом. В погребениях размещались согласно традициям мазунинского погребального обряда: найдены такие предметы в жертвенных комплексах или в составе костюма. Основное использование кольчужных изделий в женском уборе связано с накосными и нагрудными украшениями. Доступные для изучения фрагменты кольчуг из женских погребений заметно уступают по своим характеристикам целым кольчужным рубашкам мазунинских и азелинских воинов с импортным оружием. Основной массив рассматриваемых находок происходит из закрытых комплексов, которые датируются IV в. н.э. (возможно, 2-й четвертью IV - началом V в.). Близкие аналогии в использовании фрагментов кольчуг прослеживаются в германском мире.

Ключевые слова: археология, Западное Предуралье, эпоха великого переселения, могильники мазунинского типа, могильники, женский убор.

\section{FRAGMENTS OF CHAIN MAIL ARMOR IN WOMEN'S ATTIRE OF THE POPULATION OF THE MIDDLE KAMA REGION IN THE $3^{\mathrm{RD}}-5^{\mathrm{TH}}$ CENTURIES AD}

\section{O. F. Khairullina}

The paper discusses chain mail fragments in the female burial equipment of the Mazunino Culture (or Mazunino stage of the Cheganda culture of the Piany Bor cultural-historical community by R.D. Goldina) in the Middle Kama Region. The items in question are an example of the reuse and creative reinterpretation of military protective equipment, such as the lorica hamata chain mail. A total of 97 burials with woven iron rings from 12 necropolises of the Mazunino culture have been examined. Anthropological data and grave inventory indicate that this category of equipment was used exclusively by women. They were arranged in burials according to the traditions of Mazunino burial rite: such items have been found in "sacrificial" sets or as part of a costume. In general, chain mail fragments were used in women`s attire as hair or breast jewelry. The available woven iron rings from the women's graves are noticeably inferior in terms of characteristics to the chain mail shirts of the Mazunino and Azelino warriors with imported weapons. The majority of these items have been found in closed complexes dated the $4^{\text {th }}$ century $\mathrm{AD}$ (probably the second quarter of the $4^{\text {th }}-$ the early $5^{\text {th }}$ century $\mathrm{AD}$ ). Close parallels in the use of chain mail fragments can be traced in the German cultures.

Keywords: archaeology, Western Cis-Urals, the Migration period, Mazunino type burial grounds, burial grounds, female costume.

Среди основных категорий погребального инвентаря могильников мазунинского типа чегандинской культуры ПКИО (или мазунинской культуры, по Т.И. Останиной) довольно часто встречаются корродированные куски железа неопределенной формы, спекшиеся с различными бронзовыми украшениями костюма. На некоторых изделиях отчетливо просматриваются соединенные между собой звенья округлой формы, плетение которых находит ближайшие аналогии в широко распространённом типе римского и варвар- ского защитного вооружения первой половины I тыс. н. э. - кольчужных доспехах lorica hamata. Фрагменты таких предметов кольчужного плетения (далее - предметы КП) обычно фиксируются в женских погребениях в области черепа и поэтому традиционно рассматриваются в региональной археологии в качестве элементов головных уборов - накосников (Останина, 1997, с. 36-37; Красноперов, 2006, c. 85-88; Васюткин, 1980, с. 81-82). В материалах отдельных некрополей (в частности, в Тураевском I могильнике) кольчужные изде- 


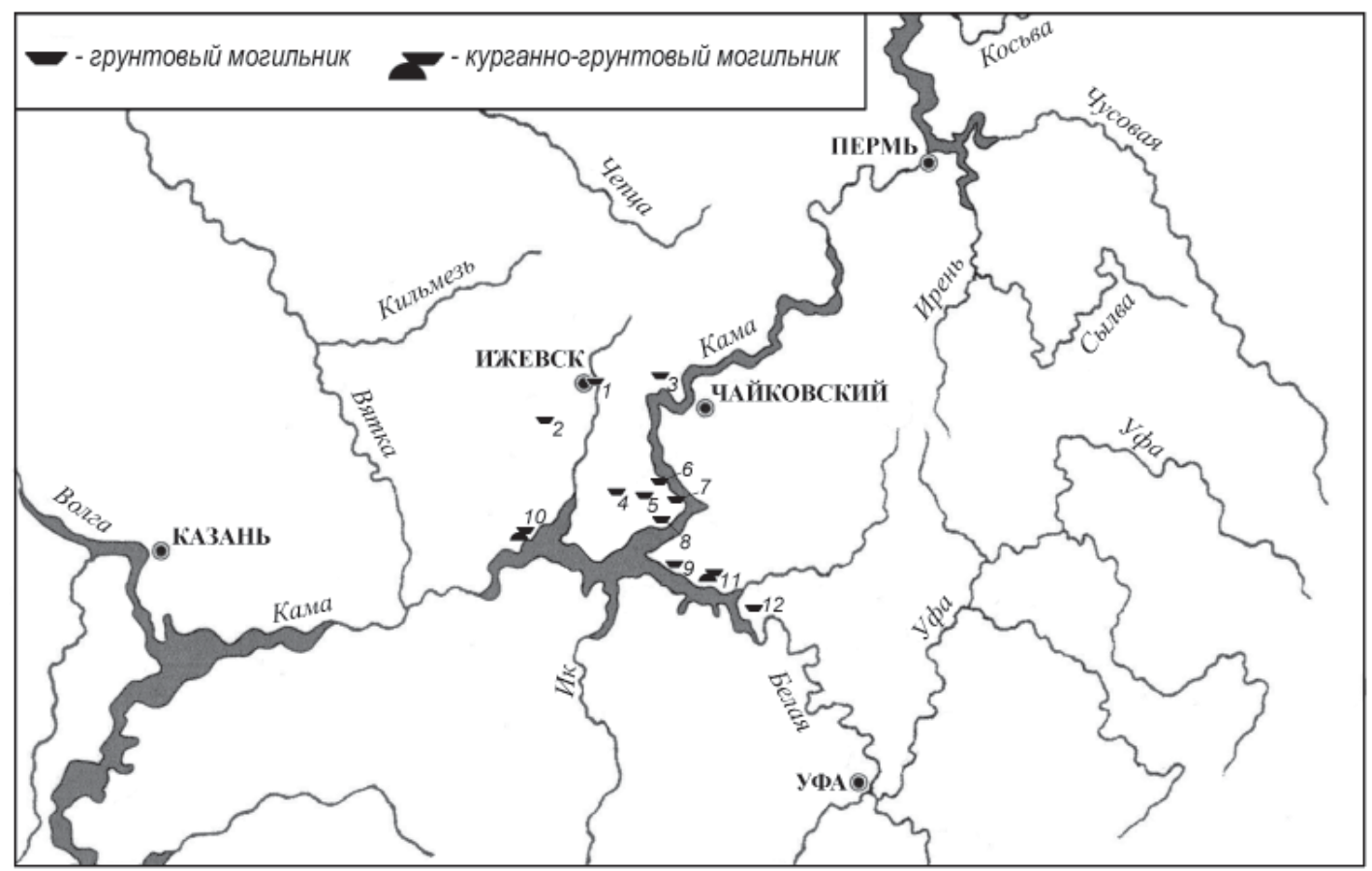

Рис. 1. Карта расположения мазунинских могильников с предметами кольчужного плетения:

1 - Ижевск; 2 - Покровское; 3 - Нива; 4 - Дубровский; 5 - Заборье; 6 - Усть-Сарапулка; 7 - Тарасово; 8 - Боярка; 9 - Старо-Кабаново; 10 - Тураево I; 11 - Старая Мушта; 12 - Ангасяк.

Fig. 1. Map of Mazunino burial grounds with chain mail fragments: 1 - Izhevsk; 2 - Pokrovskoe; 3 - Niva; 4 - Dubrovsky; 5 - Zaborie; 6 - Ust-Sarapulka; 7 - Tarasovo; 8 - Boyarka; 9 - Staroye Kabanovo; 10 - Turaevo I; 11 - Staraya Mushta; 12 - Angasyak.

лия известны в качестве «шумящих» деталей к нагрудным украшениям (Голдина, Бернц, 2010, с. 72, 126).

Ввиду того, что большинство рассматриваемых предметов КП находится в неудовлетворительном состоянии, некоторые исследователи не разграничивают данное понятие, объединяя вместе с кольчужными изделиями, сплетенными из железных и/или бронзовых колец, простые цепочки и подвески S-видной формы (Голдина, Бернц, 2010; Останина, 1997, с. 36-37, 51; Сабирова, 2019, c. 31). Вероятно, именно по этой причине за скобками, казалось бы, изученного феномена остаются нерешенными вопросы, касающиеся описания находок кольчужных предметов в мазунинских погребения ${ }^{1}$, их функционала в среднекамском женском уборе, времени проникновения (и распространения) в мазунинском обществе, аналогий и т. д. Попытаться найти ответы на некоторые из них является целью настоящей статьи.

Методика исследования и общая характеристика предметов КП. В данной работе проанализировано 97 закрытых комплексов с находками кольчужных изделий, происходящих из 12 грунтовых и курганно-грунтовых могильников мазунинского типа. Все они располагаются в бассейне Средней и отчасти Нижней Камы, на ее крупных и мелких прито- ках, в административных границах республик Удмуртия, Татарстан и Башкортостан: Тарасовский, Тураевский I, Усть-Сарапульский, Ижевский, Заборьинский, Боярский, Дубровский, Нивский, Покровский, Старо-Кабановский, Ангасякский, Старо-Муштинский могильники (рис. 1) (Голдина, 2003; Голдина, 2004a; Голдина, Бернц, 2010; Арматынская, 1986, с. 26-46; Останина, 1978, с. 92-117; 1984, с. 26-92; 1992; Бернц, 2006, с. 351-390; Васюткин, Останина, 1986, с. 64-125; Васюткин, 1980, с. 72-91; Тагиров, 2007, с. 89-110; Сунгатов, Гарустович, Юсупов, 2004).

Основная часть работы выполнена по архивным данным (полевой и отчетной документации, археологическим коллекциям), хранящимся в фондах Института истории и культуры народов Приуралья Удмуртского государственного университета, Национального музея Удмуртской Республики им. Кузебая Герда ${ }^{2}$, а также по отдельным публикациям мазунинских могильников. Характеристика кольчужных изделий (внешний диаметр колец, сечение и толщина проволоки, вид плетения, тип колец) составлена по материалам коллекций Тарасовского, Тураевского I, Боярского, Дубровского и Заборьинского могильников (30 погребений, 30,9\%). В определении рассматриваемых находок по отчетной документации решающую роль играло 


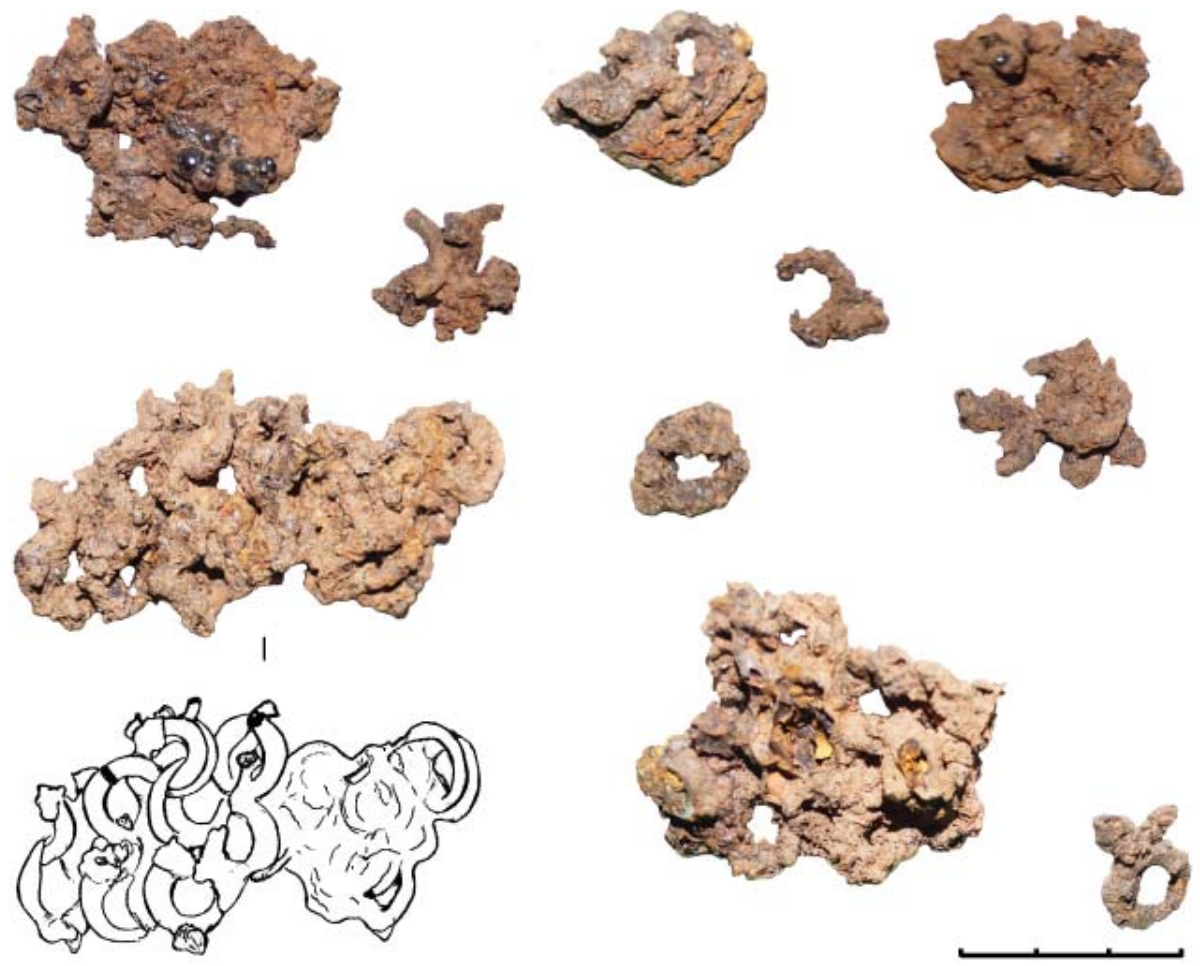

Рис. 2. Фрагменты накосного украшения кольчужного плетения из погребения 99 Дубровского могильника (железо).

Fig. 2. Details of chain mail headdress from the Dubrovskiy burial ground, grave 99 (iron).

качество фотоиллюстраций: характерное для кольчуг плетение колец удалось выявить в 42 погребениях (43,3\%; в особо редких случаях установлен тип колец, как, например, в погр. 147 Покровского могильника). Остальные комплексы (25 погребений, 25,8\%) включены в статистику по публикациям (это преимущественно могильники, расположенные на территории Башкирии, - Ангасякский, СтароМуштинский и Старо-Кабановский).

Большинство исследованных предметов КП сильно корродировано, звенья их спеклись между собой (по этой причине комплексов с фрагментами кольчуг в мазунинских могильниках в действительности было намного больше, чем это отражено в статистике). Железная проволока колец имеет округлое, реже подпрямогольное сечение толщиной 1-3 мм. Плетение стандартное - 1:4. Внешний диаметр колец $-0,7-1,2$ см (в основном до 1,0 см) (рис. 2), без проведения специального металлографического исследования типы визуально трудноопределимы. Однозначно можно лишь диагностировать клепаные кольца фрагментов кольчуг, происходящих из погр. 147 Покровского и погр. 1 Усть-Сарапульского могильников (Останина, 1980, табл. VII: 10; 1997, рис. 26: 12; Водолаго, 1984, рис. 6). Следы клепки на остальных кольчужных фрагментах отсутствуют. Предположительно кольца были спаяны (James, 2004, p. 110) или имели разомкнутые концы (Sim, Kaminski, 2012, р. 123), спекшиеся между собой (?). В могильниках, расположенных на территории Башкирии (Ангасяк, Старая Мушта), получены схожие результаты (Васюткин, 1980, с. 81-82; Тагиров, 2007, с. 91; Сунгатов, Гарустович, Юсупов, 2004, с. 63). Кроме того, на некоторых изделиях прослежено чередование рядов железных и бронзовых колец (Останина, 1978, с. 98, табл. VI: 3; Сунгатов, Гарустович, Юсупов, 2004, с. 63).

Целые экземпляры кольчуг в ареале мазунинских памятников обнаружены лишь в воинских захоронениях с импортным оружием: в погр. 1784 Тарасовского (Голдина, 2003, табл. 665-668: иллюстрации кольчуги отсутствуют; Голдина, 2004a, с. 272) и в захоронении кургана V Тураевского I ${ }^{3}$ могильников (Генинг, 1976, с. 67-72); в обоих погребениях имеются шлемы с остатками кольчужных бармиц. Тарасовская кольчуга выполнена из железных и бронзовых колец прямоугольного сечения, диаметром 1,5-1,6 см. На бронзовых звеньях имеются следы клепки4. Вероятно, кольчуга была повреждена в древности: в полевых условиях на ней были зафиксированы следы ремонта медной проволокой (Голдина, 2004a, с. 272). Кольца бармицы меньше, диаметром до 1,1 см, сечение их такое же подпрямоугольное. Кроме того, на внутренней стороне изделия фиксируется подкладка 
из кожи (?). Схожие результаты имеются и для доспеха из Тураевского кургана: диаметр звеньев составляет 1,4-1,5 см, но сведения о типах колец отсутствуют. Бармица шириной не менее 12 см, нашитая на толстую кожу (!), изготовлена из колец диметром 1,1 см; проволока звеньев толщиной 1 мм имеет круглое сечение (Генинг, 1976, с. 69-70).

Близкие параметры рассматриваемых доспехов (диаметр, сечение проволоки, тип и металлическая основа колец) встречаются и на кольчугах из азелинских воинских захоронений (Генинг, 1963, с. 73, рис. 38; Старостин, 2009 , с. 27 , рис. 43). По своим характеристикам такие «боевые» кольчуги заметно превосходят описанные выше находки из мазунинских погребений. Известно, что процесс изготовления доспехов с клепаными кольцами технологически сложен, сопоставим скорее с работой ювелира, нежели кузнеца, а «защитный индекс» выше по сравнению с кольчугами с разомкнутыми звеньями (Sim, Kaminski, 2012, p. 123, 132). При этом оба типа колец могли производиться в римских мастерских (Sim, Kaminski, 2012), хотя некоторые исследователи полагают, что техника изготовления кольчуг с разомкнутыми кольцами типична для Востока ${ }^{5}$ (особенно в Средневековье и в более позднее время) (James, 2004, p. 111).

Предметы КП в мазунинском погребальном обряде. Как было сказано выше, кольчужные изделия обнаружены в 97 мазунинских погребениях ${ }^{6}$. Антропологические определения имеются для 53 индивидуумов $(54,6 \%)$ из пяти мазунинских могильников (Боярский, Дубровский, Тарасовский, Тураевский I, Покровский). Они свидетельствуют о том, что предметы КП сопровождают преимущественно женские захоронения всех возрастов - от 12-14 до 60 и старше лет (43 костяка, 81,1\%). При этом половина всех случаев (22 костяка, 51,2\%) приходится на возрастную группу молодых девушек от 12-14 до 18-20 лет (juvenis); женщины зрелого (maturus, 35-55 лет) и пожилого (senilis, старше 55 лет) возраста занимают в этой выборке меньшинство (всего 6 костяков, 14,0\%). Скорее как исключение, изделия КП выявлены в пяти детских захоронениях в возрасте от 3-х до 10 лет $(9,4 \%$, Боярка 81Б, Тарасово 103, 116 и 783, Тураево 134) и в одном мужском погребении № 92 Покровского могильника (30-40 лет). Но при этом важно подчеркнуть, что состав этих погребальных комплексов, в том числе покровского «мужского» погребения, соответствует женскому погребальному инвентарю, для которого характерны бабочковидные фибулы, наборные пояса, головные уборы, гривны, бусы и бисер, разные типы подвесок и пронизок и т. д. Такой же специфически «женский» набор предметов типичен и для части погребений, оставшейся по ряду причин без половозрастных определений (это справедливо и для пп. 185, 1027 Тарасовского, 33 Дубровского, 135 Покровского могильников с установленным возрастом). Выбиваются из общей статистики лишь погр. 10 из Старо-Кабановского и погр. 2 кургана 5 Старо-Муштинского могильников, в комплексах которых присутствуют элементы мужского погребального инвентаря - копье, топор и удила.

Место предметов КП в погребении соответствует традициям и нормам мазунинского погребального обряда. Обнаружены они в составе жертвенных комплексов ${ }^{7}$, представляющих собой скопления личных вещей, уложенных в определенном месте при умершем (Останина, 1997, с. 25), - 43 костяка, 44,3\%. Иногда такие наборы, вероятно, заменялись единичными вещами, которые, как и в случае с жертвенными комплексами, фиксируются не на костяке (2 случая, 2,1\%). К примеpy, в погр. 81Б Боярского могильника остатки кольчужного накосника с вплетенными в него бронзовыми украшениями были найдены у ног ребенка; в погр. 1027 Тарасовского могильника кольчужная сеточка, прикрепленная к бабочковидной фибуле в качестве привески, обнаружена вместе с застежкой у черепа погребенной. В составе костюма (т. е. на костяке) предметы КП встречены в 36 случаях $(37,1 \%)$. Оба варианта размещения таких изделий зафиксированы еще в шести мазунинских захоронениях (6,2\%). В остальных случаях (10) позиция рассматриваемых предметов в погребениях остается неопределенной.

В мазунинском костюмном комплексе кольчужные изделия использовались по-разному. Один из вариантов - накосники в виде мешочков, крепившиеся с различными подвесками, пронизками и цепочками к затылочной части головного убора (Останина, 1997, с. 36-37, рис. 72, 74; Красноперов, 2006, с. 85-86, табл. 27, 4; Голдина, Черных, 2017, рис. 3) (21 случай; рис. 3). В свое время Т.И. Останиной было учтено 60 экземпляров таких украшений, обнаруженных преимущественно в Покровском, Старо-Кабановском, Ангасякском и Усть-Сарапульском могильниках (1997, с. 36-37). А.А. Красноперовым изуче- 
но свыше 30 мазунинских накосников, в числе которых имеются находки из Тарасовского и Тураевского I могильников (2006, с. 87). K этой сводке можно добавить украшения из Боярского (п. 168) и Дубровского (пп. 98В, 99) могильников.

Стоит отметить, что внешний вид рассматриваемых комплектов вряд ли соответствовал азелинским накосникам полукруглой формы, основа которых состояла из органических материалов - кожаных ремешков (Генинг, 1963, с. 54-55, рис. 23, 31; Останина, 1997, рис. 72, 74; Красноперов, 2006, табл. $27,4)$. Вероятнее всего, форма мазунинского накосника подчинялась, в первую очередь, размерам кольчужных фрагментов, которыми располагали мазунинские дамы, и напрямую зависела от свойств кольчужного полотна, производство которого в римский период имело свои отличительные особенности ${ }^{8}$. Это подтверждается конкретными находками накосников подтреугольной, подпрямоугольной и конусообразной формы, обнаруженных in situ в пп. 135, 147 и 220 Покровского могильника (Останина, 1992, рис. 20: 5; 25: 2, 3). Такая же «геометрическая» (треугольная) форма расправленного (?) накосного украшения с тканевой основой зафиксирована в жертвенном комплексе погр. 80 Ангасякского могильника (Тагиров, 2007, с. 91, рис. 3: II-5; 12:5).

Другой способ применения кольчужных изделий в мазунинском костюме связан с использованием их в качестве привесок к нагрудным украшениям (22 случая). Основой такого шумящего аксессуара являлась фибула или сюльгама, к игле или пружине которой подвешивались кольчужные привески вместе с различными подвесками, бисером, цепочками. Положение их относительно застежки варьирует: подвязывали привески только к одной (например, Тураево 135, 137; Тарасово $783,1786)$ или к обеим сторонам фибулы (Тарасово 1691; Тураево 29, 66, 250; Нива 150А). В некоторых случаях кольчужные изделия могли нанизывать и на среднюю часть иглы, опуская вниз примерно по центру застежки (Тарасово 383, Тураево 134). В общих чертах описываемое составное шумящее украшение на женском платье выглядело следующим образом: фибулу (или сюльгаму), как правило, закрепляли по центру груди, а шумящие украшения свободно свисали приблизительно до уровня живота/тазовых костей, поскольку длина некоторых сохранившихся кольчужных экземпляров составляет 20-25 см: например, в пп. 66, 101, 250 Тураевского I могильника (Голдина, Бернц, 2010, рис. 12: 2, табл. 49, 51, $74,75,174,175)$.

Третий вариант размещения кольчужных изделий в погребениях довольно необычен. В него включены случаи с отдельными находками мелких или крупных фрагментов кольчуг, которые обнаружены на теле костяка вне какой-либо связи с застежками (или другими вещами), крепившими их к костюму (8 случаев). Некоторые из кольчужных фрагментов найдены в области грудной клетки или пояса (Тураево 14, 83 - мелкие фрагменты, 107 14,0×7,5 см; Старая Мушта, раскоп 1, погр. 4 - 22,0×10,0 см, Ангасяк 93 - ок. 15,0×7,0-8,0 см) и, очевидно, являются нагрудными (или накосными?) украшениями. Другие зафиксированы на руках (Тураево 39 - ок. 70,0×10,0 см) или ногах умерших в виде вытянутых кольчужных «лент» (Покровский 147 и $199-$ $50,0 \times 7,0-10,0$ см) рядом с наборными поясами. Объяснить значение указанных находок довольно трудно. Вполне вероятно, такие кольчужные полосы могли служить «шумящим» украшением к наборному поясу (по аналогии с кольчужными привесками к фибулам) либо нашиваться на одежду. Не исключено, что разложенные в погребениях крупные куски кольчуг укладывались в соответствии с традициями мазунинского погребального обряда, как и вытянутые вдоль тела наборные пояса.

Хронология мазунинских погребений с предметами КП. Рассматриваемые кольчужные изделия, судя по хронологическим выкладкам Т.И. Останиной, существовали в мазунинском обществе на протяжении IV-V вв. н. э. (1997, рис. 51: 39, 72, 74). Анализ инвентаря позволяет уточнить предложенную датировку.

«Ранних» наборов с бабочковидными фибулами Останина 1-2 (1997, рис. 51: 53) и поясной гарнитурой с раковинами и накладками типа Останина-1, Останина-3а (1997, рис. 51: 43, 49) в представленной выборке немного: пп. 130, 383, 783 Тарасовского и погр. 30 Заборьинского могильников. В этой группе впервые появляются характерные для «развитого мазунино» головные уборы в виде лент с бронзовыми пронизками-обоймами, украшенными выпуклыми полугорошинами (Тарасово, 383; Сабирова, 2019, рис. 49: 19). Датируются фибулы Останина 1-2 достаточно широко - IV в. н. э. (Останина, 1997, рис. 51: 53; Голдина, Бернц, 2017, с. 55, рис. 4: 30), однако инвентарь погребений с данными 
застежками тяготеет к более раннему периоду - ко 2-й пол. III в. или к рубежу III-IV вв. (Голдина, Бернц, 2017, рис. 3, 6; Сабирова, 2019 , с. 44, 45).

Остальные наборы в рассматриваемой выборке отнесены к «поздней» хронологической группе, для которой характерны различные типы местных фибул: Останина 1-3, 1-4, 1-5 (примеч. 9) (1997, рис. 51: 5, 24, 25. примечания 9), Останина-2 (1997, рис. 51: 23; Сабирова, 2019, с. 22, рис. 25: 2, 26-29), Останина-3 (1997, рис. 51: 22; Сабирова, 2019, с. 22-23, рис. 30-31), «трехщитковые» (Сабирова, 2019, с. 23, рис. 32). С данными застежками встречаются головные уборы с описанными выше пронизками-обоймами, которые украшались бляшками полусферической формы (Останина-2б; 1997, рис. 51: 29). Такими изделиями вместе с нанизанными на кожаный шнур кольцеобразными пронизками Останина 1-5 (1997, рис. 51:2) нередко оформляли рукава верхней (или нижней) одежды (Красноперов, 2006, с. 181, 182). Для данного периода характерны ножны типа Останина-3 (1997, рис. 51: 14), железные и бронзовые шейные пластинчатые гривны (Сабирова, 2019, рис. 53: 9, 13), гривны с ромбическим сечением (Сабирова, 2019, рис. 53: 5), пронизки-медведи и пронизки-уточки (Останина, 1997, рис. 51: 6), а также некоторые другие категории вещей.

Поясные и обувные наборы местного производства отличаются многообразием типов накладок (Останина, 1997, рис. 51: 1, 4, 7, 10, 48, 84). Железные щитковые пряжки имеют прямоугольные или зауженные к центру щитки, овальные или В-образные рамки (Останина, 1997, рис. 51: 42, 64). Наконечники ремней прямоугольные, с выемками по бокам (1997, рис. 51: 57) или «наборные», состоящие из нескольких пластин, согнутых пополам (1997, рис. 12: 15). Особенностью данного периода можно считать соединение железа и цветных металлов при изготовлении поясной гарнитуры и местных типов фибул, которые активно начинают украшаться бронзовыми штифтами-полугорошинами (прием, который широко распространяется на позднесарматской поясной гарнитуре в конце III - первых десятилетиях IV в.; Малашев, 2000, c. 201, 207).

Хроноиндикаторами в данных комплексах выступают поясные наборы из цветных металлов, аналогичные некоторым позднесарматским образцам: типы П9, П10, Н10 по В.Ю. Малашеву (2000, с. 196, 197, 201, 202).
Это пряжки с овальными щитками, которые имеют фасетированные или гладкие язычки с низкими уступами у основания сзади (П9): Покровское 109B, 125, 147, 149, 314; Тураево 39, 204; Дубровский 203; Тарасово 169А, Старо-Кабаново 35, 36, 69), а также пряжки с более массивными язычками, охватывающими рамку до середины ее сечения, с высокими уступами/рельефными выступами у оснований язычков (П10): Покровское 109В, Старо-Кабаново 80, 107, 135). В позднесарматских комплексах подобная поясная гарнитура встречается с кон. III в. и до сер. IV в. н. э. (Малашев, 2000, с. 205-207, рис. 2). Пряжки типа П10 доживают и до раннего V в. (Малашев, 2000, с. 203-205, рис. 2).

Из «поздних» погребений происходят находки импортных фибул. В погребении 3 кургана 15 Старо-Муштинского могильника обнаружена двучленная прогнутая подвязная фибула типа Амброз 16/2-1-3 длиной до 7,0 см (Амброз, 1966, с. 64-66). По мнению О.А. Гей и И.А. Бажана, такие застежки в черняховских могильниках существуют на протяжении периодов 3 (310-350 гг.) и 4 (350-375 гг.) (1997, с. 43, 44, табл. 71). Е.Л. Гороховский относит их к фазам 4, 5 (тип Б3б, 350-400, 375/380-420/430 гг.), а О.В. Шаров датирует горизонтом 3 (тип 3, 310/320350/360 гг.) (Гороховский, 1988, с. 35, 44-45; Шаров, 1992. с. 183, 197, 198, табл. VIII, IX). Из погребения 125 Покровского могильника происходит «Т-образная» фибула (по определению T.М. Сабировой, тип Корзухина IV-1: 2019, с. 26), которая по разработкам Е.Л. Гороховского, А.И. Кубышева, Р.В. Терпиловского может датироваться в рамках 1-й пол. IV в. н. э. (1999, с. 145).

Таким образом, исходя из анализа закрытых комплексов погребений с предметами КП, можно сделать вывод о том, что рассматриваемые изделия являются неотъемлемой частью женского костюмного комплекса периода «развитого (позднего) мазунино». Однако первый опыт их использования в среднекамском уборе соотносится с началом выхода из употребления «ранней» группы вещей и, вероятно, приходится на рубеж III-IV вв. или на ранний IV век (?). Тогда как основной массив рассматриваемых находок, учитывая датировки импортных изделий (или местных образцов, копирующих импорты) и имеющиеся радиоуглеродные даты (погр. 176 Боярского могильника), попадает в закрытые комплексы только в IV в. н. э. (возможно, во 2-й четв. IV-нач. V в.). 


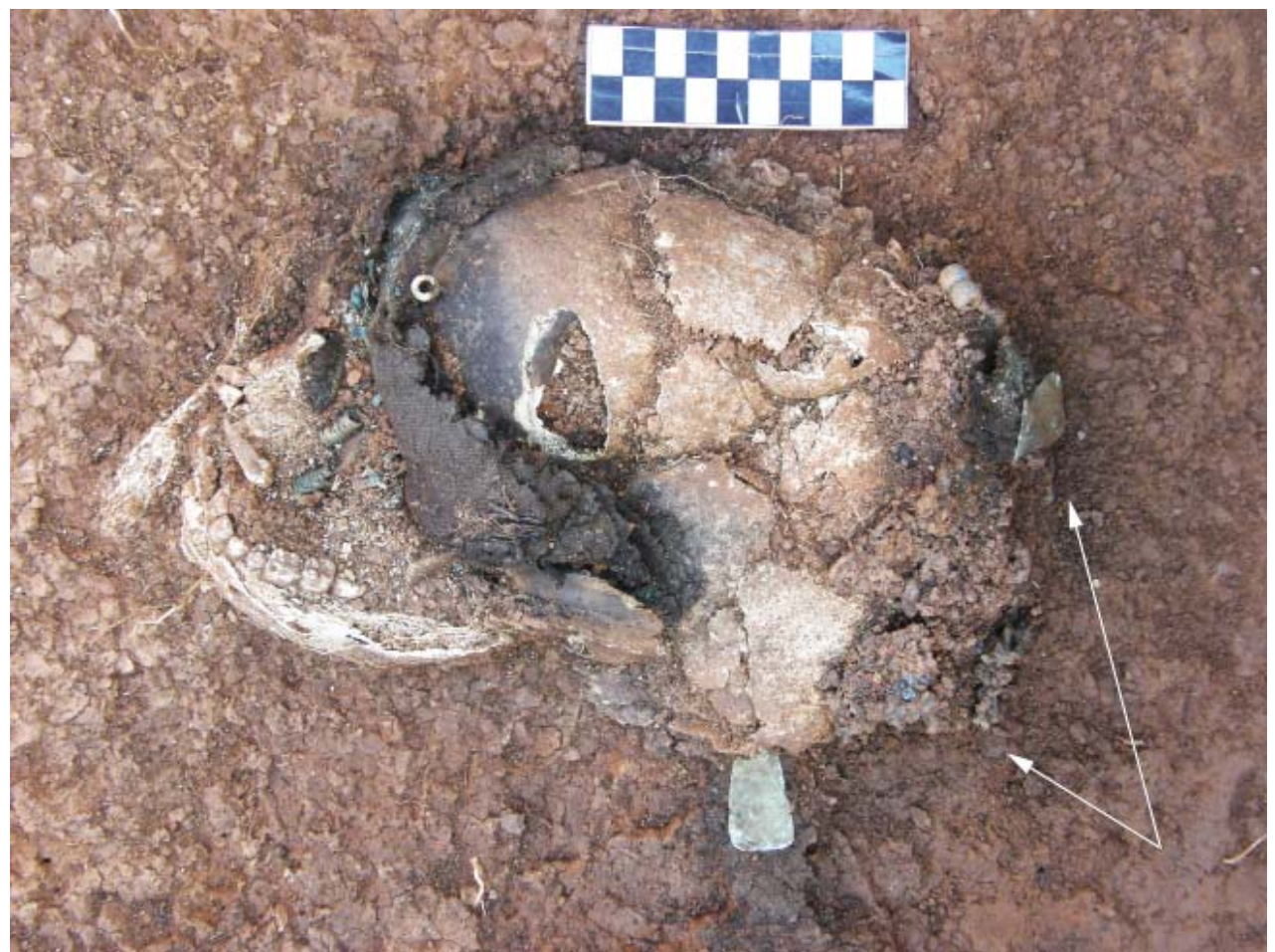

Рис. 3 Фиксация накосного кольчужного украшения in situ в погребении 99 Дубровского могильника. Фото Е.М. Черных

Fig. 3. Chain mail headdress from the Dubrovskiy burial ground. Fragment of grave 99 in situ (photo by E.M. Chernykh)

Выводы. Кольчужные изделия в мазунинском женском уборе финала раннего железного века представляют собой яркий пример вторичного использования вещей, распространенных в инокультурной среде в качестве защитных элементов воинской субкультуры - кольчужных доспехов lorica hamata. Оказавшись в мазунинском обществе в начале IV в. н. э. (?), данные предметы не были востребованы по их прямому назначению, но оказались творчески переосмыслены и включены в состав женского костюма (то же на тысячелетие произошло с русскими монетами) преимущественно в качестве элементов головных уборов (накосников) или шумящих нагрудных украшений.

В синхронных лесных культурах ВолгоКамья аналогичное использование изделий КП пока не зафиксировано (нет здесь и такого количества фрагментов кольчуг, которое демонстрируют среднекамские могильники). Близкие культурные параллели обнаружены за тысячи километров от Среднего Прикамья, в ареале пшеворской (Czarnecka, 1994, p. 245-253) и черняховской культур (Гопкало, Тылищак, с. 86-87), а также в могильниках крымских предгорий (Храпунов, 2010, с. 459-462). Разрозненные фрагменты кольчуг здесь фиксируются в женских (и/или в детских) захоронениях, но датируются разным временем: в пшеворской культуре 2-й пол. II - ранним III в. (Czarnecka, 1994, p. 246; Kontny, 2016, p. 170-171), в крымских могильниках - II - 1-й пол. III в. н. э. (Храпунов, 2010, с. 460), в черняховской культуре - IV в. н. э. (Гопкало, Тылищак, 2010, c. 86-87).

Столь близкие аналогии в использовании фрагментов кольчуг мазунинским населением с одной стороны и германским миром с другой вполне можно объяснить контактами, характер которых пока не совсем ясен. Не исключено, что доступ к кольчужным доспехам мог быть открыт во время какогото значимого события (война, военный поход - ?), которое вряд ли напрямую затронуло мазунинское общество, но имело непосредственное отношение к участникам тех событий - потенциальным «партнерам» мазунинцев. Очевидно, будет уместным представить мнение польских археологов, которые считают, что изготовление кольчужных украшений в пщеворской культуре стало возможным в ходе Маркоманнских войн, когда римская кольчуга стала доступна населению (Kontny, 2016, p. 184). В любом случае, интерпретация столь удивительного культурного явления на берегах Средней Камы, далеких от основных событий эпохи Переселений, еще ждет своего часа. 


\section{Примечания:}

1. Отчасти эта работа проделана башкирскими археологами на материалах Ангасякского и Старо-Муштинского могильников (Васюткин, 1980, с. 81-82; Сунгатов, Гарустович, Юсупов, 2004, с. 63; Тагиров, 2007, с. 91).

2. Выражаю искреннюю благодарность к. и. н., профессору УдГУ Е.М. Черных за возможность использования в настоящем исследовании архивных материалов Дубровского и Боярского могильников, а также публикации накосного украшения из погребения 99 Дубровского могильника. Автор также признателен ученому секретарю БУК УР «Национальный Музей УР» Ю.А. Перевозчикову за возможность работать с архивными фондами музея.

3. Мелкие фрагменты кольчуги найдены в разграбленных курганах VI и VIII этого же некрополя. На шлеме из погребения 1а кургана VII имеется кольчужная бармица длиной 18-20 см с диаметром колец 1,3-1,5 см (Генинг, 1976, с. 73-76, рис. 18).

4. Описание данной кольчуги приведено в работе А.П. Зыкова (2016, с. 225). Повторный осмотр изделия позволил уточнить размеры и сечение проволоки колец.

5. Реальные находки кольчужных доспехов на территории Римского Востока или Сасанидской Империи практически отсутствуют, за исключением прекрасно сохранившихся артефактов из знаменитой крепости ДураЭвропос (Сирия), захваченной в 256 г. войсками Сасанидов. Здесь обнаружены различные фрагменты кольчуг (в том числе целая кольчужная рубашка «персидского» воина) «тонкого» плетения: проволока звеньев имеет округлое или прямоугольное сечение, диаметр колец варьируется от 0,6 до 1,0 см. Явно клепаных колец здесь не обнаружено, хотя металлографического исследования кольчуг не проводилось. (James, 2004, p. 110-111, 116).

6. Боярка (81Б, 89, 168), Тарасово (103, 116, 130, 136, 169A, 185, 223, 383, 392, 783, 1027, 1691, 1760, 1786, 1792), Тураево I (12, 14, 29, 39, 66, 73, 83, 101, 107, 134, 135, 137, 204, 222, 250, 257), Дубровский $(33,63,98 \mathrm{~B}, 99,136$, $168,175,203)$, Усть-Сарапулка $(1,38,45,52)$, Ижевск (96), Нива (150А), Заборье (30), Старо-Кабаново (10, 35, 36, $40,69,80,81,92,98,107,135)$, Ангасяк $(4,10,13,17,18,49,64,80,82,93)$, Покровское $(60,71,92,94,95,109 \mathrm{~B}$, $125,135,147,149,199,220,247,253,258$ A, 296, 303, 313, 314, 317, 322, 330, 338), Старая Мушта (к. 2 погр.5, к. 15 погр. 3, к. 17 погр. 1, раскоп 1 погр. 4).

7. Р.Д. Голдиной такие комплекты вещей названы «подарочными наборами» и определяются как подарки «умершей жене, невесте, мужу, сыну для загробной жизни» (20046, с. 209).

8. Техника изготовления кольчуг римского времени существенно отличается от изделий позднего Средневековья и раннего Нового времени. Конструкция наиболее сохранившегося экземпляра II - начала III в. из Вимосе (Vimose, Дания) довольно проста, имеет явные параллели с широко распространённым типом одежды того периода римской туникой: полотно кольчуги прямоугольное, имеет одинаковую ширину вверху, в центре и внизу, разрезы по подолу и горизонтальную щель в качестве выреза горловины, а также некоторые другие признаки, отличные от кольчужных доспехов эпохи Средневековья и раннего Нового времени. Изготовление последних отличается разнообразием приемов и техник (например, использование треугольных вставок для расширения/стягивания кольчужной одежды, изменение размеров колец для регулирования веса, размещение кольчужного полотна под углом вокруг подмышек), о которых в римское время практически ничего не было известно (отсутствуют данные приемы и на кольчуге из Вимосе) (подробнее: Wijnhoven, 2015, pp. 555-563).

9. Данный тип фибулы обнаружен в погр. 176 Боярского могильника, для которого имеется калиброванная радиоуглеродная дата (Le-8529) - 341-414 AD (62,1\%), 318-430 AD (77,6\%) (Черных, Хайруллина, 2018, рис. 1: 3).

\section{ЛИТЕРАТУРА}

Амброз А.К. Фибулы Юга Европейской части СССР. III в. до н. э. - IV в. н. э. / САИ. Вып. Д1-30. М.: Наука, 1966. 142 с.

Арматынская O.B. Усть-Сарапульский могильник // Приуралье в древности и средние века / Отв. ред. А.А. Тронин. Устинов: Удмуртский университет, 1986. С. 26-46.

Берни B.A. К вопросу о традиционных элементах погребального обряда финно-угорского населения эпохи великого переселения народов Удмуртского Прикамья (по материалам Заборьинского грунтового могильника) // Взаимодействие народов Евразии в эпоху Великого переселения народов / Отв. ред. Р.Д. Голдина. Ижевск: УдГУ, 2006. С. 351-390.

Васюткин C.M. Ангасякский могильник - ранний памятник бахмутинской культуры // Памятники эпохи средневековья в Верхнем Прикамье / Отв. ред. В.Ф. Генинг. Ижевск: УдГУ, 1980. С. $72-91$.

Васюткин С.М., Останина Т.И. Старо-Кабановский могильник - памятник мазунинской культуры в Северной Башкирии // Вопросы истории и культуры Удмуртии / Сост., науч. ред. Т.И. Останина. Устинов: Удмуртия, 1986. С. 64-125.

Водолаго Н.В. Отчет об исследованиях Усть-Сарапульского могильника в Сарапульском районе Удмуртской АССР в 1983 году / Архив ИИКНП. Ф.2. Д. 175.

Гей О.А., Бажан И.А. Хронология эпохи «готских походов» (на территории Восточной Европы и Кавказа) / Науч. ред. М.Б. Щукин. М.: Наука, 1997. 144 с.

Генинг В.Ф. Азелинская культура III-V вв.: очерки истории Вятского края в эпоху переселения народов / ВАУ. Вып. 5. Ижевск, 1963. 195 с.

Генинг В.Ф. Тураевский могильник V в. н.э. (захоронение военоначальников) // Из археологии Волго-Камья / Отв. ред. А.Х. Халиков. Казань: ИЯЛИ КФАН СССР, 1976. С. 67-72. 
Голдина E.B., Черных E.M. Бусы Дубровского могильника IV-V вв. в Среднем Прикамье: классификация и использование // Поволжская археология. 2017. № 1(19). С. 238-256.

Голдина Р.Д. Тарасовский могильник I-V вв. на Средней Каме. Т. II / МИКВАЭ. Т. 11. Ижевск: Удмуртия, 2003. $721 \mathrm{c.}$

Голдина Р.Д. Тарасовский могильник I-V вв. на Средней Каме. Т. I / МИКВАЭ. Т. 10. Ижевск: Удмуртия, 2004а. 318 с.

Голдина Р.Д. Древняя и средневековая история удмуртского народа. Ижевск: Удмуртский университет, 20046. 464 с.

Голдина Р.Д., Бернц В.А. Тураевский I могильник - уникальный памятник эпохи великого переселения народов в Среднем Прикамье (бескурганная часть) // МИКВАЭ. Т. 17. Ижевск: Изд-во «Удмуртский университет», 2010. 499 с.

Голдина Р.Д. Берни В.А. Хронология женских погребений III-V вв. Тарасовского могильника // Поволжская археология. 2017. № 2(20). С. 42-72.

Гопкало O.B., Тылищак В.C. Римские импорты из металла на могильнике Чернелив-Русский // Германия-Сарматия. Выпуск II / Ред. О.А. Щеглова и др. Курск; Калининград: Калининградский областной историко-художественный музей; Курский государственный областной музей археологии, 2010. С. 79-95.

Гороховский Е.Л. Хронология черняховских могильников лесостепной Украины // Труды V Международного конгресса археологов-славистов / Глава ред. кол. Б.А. Рыбаков. Киев: Наукова думка, 1988. C. 34- 46 .

Гороховский Е.Л., Кубышев А.И., Терпиловский Р.В. Украшения круга выемчатых эмалей из села Воронькив на Киевщине // Сто лет черняховской культуре / Отв. ред. М.Е. Левада. Киев: ИА НАН Украины, 1999. С. 145-149.

Зыков А.П. Защитное вооружение Тарасовского могильника (шлемы и доспехи) // Археологическое наследие Урала: от первых открытий к фундаментальному научному знанию (XX Уральское археологическое совещание): Материалы Всероссийской (с международным участием) научной конференции / Отв. ред. Е.М. Черных. Ижевск: Удмуртский университет, 2016. С. 223-225.

Красноперов А.А. Костюм населения чегандинской культуры в Прикамье (II в. до н. э. - V в. н. э.). Дисс... канд. ист. наук. Ижевск, 2006. 269 с.

Малашев В.Ю. Периодизация ременных гарнитур позднесарматского времени // Сарматы и их соседи на Дону / Материалы и исследования по археологии Дона. Вып. 1 / Отв. ред. Ю.К. Гугуев. Ростовна-Дону: Терра, 2000. С. 194-232.

Останина Т.И. Нивский могильник // Материалы к ранней истории населения Удмуртии / Отв. ред. М.Г. Иванова. Ижевск: Удмуртия, 1978. С. 92-118.

Останина Т.И. Отчет о раскопках Покровского могильника (дер. Сизяшур Мало-Пургинского района УАССР), проведенных летом 1980 года / НА БУК УР «Национальный Музей УР». № 547а.

Останина Т.И. Два памятника мазунинской культуры в центральной Удмуртии // Поиски, исследования, открытия / Науч. ред. Т.И. Останина. Ижевск: Удмуртия, 1984. С. 26-92.

Останина Т.И. Покровский могильник IV-V вв.. Каталог археологической коллекции. Ижевск: б/и, 1992. $93 \mathrm{c}$.

Останина Т.И. Население Среднего Прикамья в ІІІ-V вв. Ижевск: УИИЯЛ УрО РАН, 1997. 327 с.

Сабирова T.M. Фибулы Среднего Прикамья первой половины I тыс. н. э. Ижевск: Шелест, 2019. 238 с.

Старостин П.Н. Рождественский V могильник / Археология евразийских степей. Вып. 9. Казань: ИИ АН РТ, 2009. 144 с.

Сунгатов Ф.А., Гарустович Г.И., Юсупов Р.М. Приуралье в эпоху великого переселения народов (Старо-Муштинский курганно-грунтовый могильник). Уфа: ГУП «Уфимский полиграфкомбинат», 2004. $172 \mathrm{c}$.

Тагиров Ф.М. Новые исследования Ангасякского могильника // УАВ. 2007. № 6-7. С. 89-110.

Черных E.M., Хайруллина О.Ф. Боярский («Арай») могильник - новый памятник эпохи великого переселения народов в Прикамье // Археология Евразийских степей. 2018. № 1. С. 86-106.

Храпунов Н.И. Изделия, сплетенные из железных колец // Боспорские исследования. 2010. № 23. C. $459-462$.

Шаров О.В. Хронология могильников Ружичанка, Косаново, Данчены и проблема датировки черняховской культуры // Проблемы хронологии эпохи латена и римского времени / Ред. М.Б. Щукин, О.А. Гей. СПб: Ойум, 1992. С. 158-207.

Czarnecka $\mathrm{K}$. The reuse of Roman military equipment in barbarian context. A chain-mail souvenir? // Journal of Roman Military Equipment Studies. 1994. Vol. 5. 245-253.

James $S$. The excavations at Dura-Europos conducted by Yale University and the French Academy of Inscriptions and Letters 1928 to 1937. Final Report VII. The Arms and Armour and other Military Equipment. London: The British Museum Press, 2004. 304 p. 
Kontny B. Przeworsk culture society and its long-distance contacts, AD 1-350 // Past Societies. Vol. 4 / Ed. A. Rzeszotarska-Nowakiewicz. Warszawa: Institute of Archaeology and Ethnology, Polish Academy of Sciences, 2016. P. 164-216.

Sim D., Kaminski J. Roman imperial armour: the production of early imperial military armour. Oxford: Oxbow Books, 2012. 201 p.

Wijnhoven M.A. Laid out Flat: Mail Making in the Roman Period// Limes XXIII: proceedings of the 23rd International Congress of Roman Frontier Studies Ingolstadt 2015 / Eds. Sommer C. Sebastian, Matešic Suzana. Mainz: Nünnerich-Asmus Verlag, 2018. P. 555-563.

\section{Информация об авторе:}

Хайруллина Ольга Фаридовна, аспирант кафедры истории Удмуртии, археологии и этнологии, Институт истории и социологии, Удмуртский государственный университет (г. Ижевск, Россия); olenbka93@bk.ru

\section{REFERENCES}

Ambroz, A. K. 1966. Fibuly Iuga Evropeiskoi chasti SSSR. III v. do n.e. - IV v. n.e. (The Fibulae from South of the USSR European part). Series: Svod Arkheologicheskikh Istochnikov (Corpus of Archaeological Sources). D1-30. Moscow: "Nauka" Publ. (in Russian).

Armatynskaia, O. V. 1986. In Tronin, A. A. (ed.). Priural'e v drevnosti i srednie veka (Cis-Urals in Antiquity and Middle Ages). Ustinov: Udmurt State University, 26-46 (in Russian).

Bernts, D. G. 2006. In Goldina, R. D. (ed.). Vzaimodeistvie narodov Evrazii v epokhu velikogo pereseleniia narodov (Interaction of Eurasian Peoples in the Great Migrations Age). Izhevsk: Udmurt State University, 351-390 (in Russian).

Vasiutkin, S. M. 1980. In Gening, V. F. (ed.). Pamiatniki epokhi srednevekov'ia v Verkhnem Prikam'e (Medieval Sites in the Upper Kama Area). Izhevsk: Udmurt State University, $72-91$ (in Russian).

Vasiutkin, S. M., Ostanina, T. I. 1986. In Ostanina, T. I. (ed.). Voprosy istorii i kul'tury Udmurtii (Issues of History and Culture of Udmurtia). Ustinov: Udmurtiia, 64-125 (in Russian).

Vodolago, N. V. 1983. Otchet ob issledovaniiakh Ust'-Sarapul'skogo mogil'nika v Sarapulskomskom raione Udmurtskoi ASSR v 1983 godu (Report on the Studies of the Ust-Sarapul Murial Ground in the Sarapul District of the Udmurt ASSR in 1983). Archive of the Institute of the History and Culture of the Cis-Ural Peoples at the Udmurt State University. Fund 2, dossier 175 (in Russian).

Gaj, O. A., Bažan, I. A. 1997. Khronologiia epokhi "gotskikh pokhodov» (na territorii Vostochnoi Evropy $i$ Kavkaza) (Chronology of the Epoch of "Gothic Raids" (on the Territory of Eastern Europe and Caucasus)). Moscow: "Nauka" Publ., (in Russian).

Gening, V. F. 1963. Azelinskaia kul 'tura III-Vvv. Ocherki istorii Viatskogo kraia v epokhu velikogo pereseleniia narodov (Azelino Culture of $3^{\text {rd }}-5^{\text {th }}$ Centuries: Essays on History of the Vyatka Area in the Great Migrations). Series: Voprosy arkheologii Urala (Problems of Archaeology of Ural) 5. Izhevsk (in Russian).

Gening, V. F. 1976. In Khalikov, A. Kh. (ed.). Iz arkheologii Volgo-Kam'ia (From the Volga-Kama Archaeology). Kazan: Institute for Language, Literature and History, Kazan Branch of the USSR Academy of Sciences, 67-72 (in Russian).

Goldina, E. V., Chernykh, E. M. 2017. In Povolzhskaya arkheologiya (Volga River Region Archaeology) 19 (1), 238-256 (in Russian).

Goldina, R. D. 2003. Tarasovskii mogil'nik I-Vvv. na Srednei Kame (Tarasovo Burial Ground of $1^{\text {st }}-5^{\text {th }}$ Centuries in the Middle Kama Region) II. Izhevsk: "Udmurtiia" Publ. (in Russian).

Goldina, R. D. 2004. Tarasovskii mogil'nik I-V vv. na Srednei Kame (Tarasovo Burial Ground of $1^{\text {st }}-5^{\text {th }}$ centuries in the Middle Kama Region) 1. Izhevsk: "Udmurtiia" Publ. (in Russian).

Goldina, R. D. 2004b. Drevniaia i srednevekovaia istoriia udmurtskogo naroda (Antique and Medieval History of the Udmurt People). Izhevsk: Udmurt State University (in Russian).

Goldina, R. D., Bernts, V. A. 2010. Turaevskii I mogil'nik - unikal'nyi pamiatnik epokhi velikogo pereseleniia narodov v Srednem Prikam'e (beskurgannaia chast') (Turaevo I Burial Ground, the Unique Site of the Great Migrations in the Middle Kama Area (the Part without Kurgans). Series: Materialy i issledovaniia Kamsko-Viatskoi arkheologicheskoi ekspeditsii (Proceedings and Research of the Kama-Vyatka Archaeological Expedition) 17. Izhevsk: Udmurt State University (in Russian).

Goldina, R. D., Bernts, V. A. 2017. In Povolzhskaya arkheologiya (Volga River Region Archaeology) 20 (2), 42-72 (in Russian).

Gopkalo, O. V., Tylishchak, V. S. 2010. In Shcheglova, O. A. et al. (eds.). Germaniia-Sarmatiia (Germania - Sarmatia) 2. Kursk, Kaliningrad: Kaliningrad Regional History and Art Museum; Kursk State Regional Museum of Archaeology, 79-95 (in Russian).

Gorokhovskii, E. L. 1988. In Rybakov, B. A. (ed.). Trudy V Mezhdunarodnogo kongressa arkheologovslavistov (Proceedings of the $5^{\text {th }}$ International Congress of Slavicist Archaeologists). Kiev: "Naukova dumka" Publ., 34-46 (in Russian). 
Gorokhovskii, E. L., Kubyshev, A. I., Terpilovsky, R. V. 1999. In Levada, M. E. (ed.). Sto let cherniakhovskoi kul'ture (The Hundredth Anniversary of Chernyakhov Culture). Kiev: Institute of Archaeology, National Academy of Sciences of Ukraine, 145-149 (in Russian).

Zykov, A. P. 2016. In Chernykh, E. M. (ed.). Arkheologicheskoe nasledie Urala: ot pervykh otkrytii $k$ fundamental'nomu nauchnomu znaniiu (XX Ural'skoe arkheologicheskoe soveshchanie): Materialy Vserossiiskoi (s mezhdunarodnym uchastiem) nauchnoi konferentsii (Archeological heritage of the Urals: from the first discoveries to fundamental scientific knowledge (XX Ural archeological meeting): The materials of all-Russia (with international participation) scientific conference). Izhevsk: Udmurtia University, 223-225 (in Russian).

Krasnopeorov, A. A. 2006. Kostium naseleniia chegandinskoi kul'tury v Prikam'e (II v. do n.e. - Vv. n.e.) (Costume of Residents of the Cheganda Culture in the Kama River Basin ( $2^{\text {nd }}$ Century BC $-5^{\text {th }}$ Century AD)). $\mathrm{PhD}$ Diss. Izhevsk (in Russian).

Malashev, V. Yu. 2000. In Guguev, Yu. K. (ed.). Sarmaty i ikh sosedi na Donu (Sarmatians and Their Neighbors on the Don). Series: Materialy i issledovaniia po arkheologii Dona (Materials and Research of the Don Archaeology) I. Rostov-on-Don: "Terra” Publ., 194-232 (in Russian).

Ostanina, T. I. 1978. In Ivanova, M. G. (ed.). Materialy k rannei istorii naseleniia Udmurtii (Materials for the Early History of Population of Udmurtia). Izhevsk: "Udmurtiia" Publ., 92-118 (in Russian).

Ostanina, T.I. 1980. Otchet o raskopkakh Pokrovskogo mogil'nika (der. Siziashur Malo-Purginskogo raiona UASSR), provedennykh letom 1980 goda (Report on the Excavations of Pokrovsky Burial Ground (Sizyashur Village of the Malopurginsky District of the Udmurt Autonomous Soviet Socialist Republic) in the Summer of 1980)). Scientific Archive of the National Museum of the Udmurt Republic. Inv. no. 547a. (in Russian).

Ostanina, T. I. 1984. In Ostanina, T. I. (ed.). Poiski, issledovaniia, otkrytiia (Searches, Studies, Discoveries). Izhevsk: "Udmurtiia" Publ., 26-92 (in Russian).

Ostanina, T. I. 1992. Pokrovskii mogil'nik IV-V vv. (Pokrovsky Burial Ground of the 4th-5th Centuries.). Izhevsk (in Russian).

Ostanina, T. I. 1997. Naselenie Srednego Prikam 'ia v III-Vvv. (Population of the Middle Kama Region in $3^{\text {rd }}-5^{\text {th }}$ Centuries $A D$ ). Izhevsk: Udmurt Institute of the History, Language and Literature, Ural Branch of the Russian Academy of Sciences (in Russian).

Sabirova, T. M. 2019. Fibuly Srednego Prikam'ia v pervoi polovine I tys. n.e. (Fibulae of the Middle Kama Area in the First Half of I Millennium AD). Izhevsk: "Shelest" Publ. (in Russian).

Starostin, P. N. 2009. Rozhdestvenskii V mogil'nik (Rozhdestveno $5^{\text {th }}$ Burial Ground). Series: Arkheologiia evraziiskikh stepei (Archaeology of the Eurasian Steppes) 19. Kazan: Institute for History named after Shigabuddin Mardzhani, Tatarstan Academy of Sciences (in Russian).

Sungatov, F. A., Garustovich, G. I., Iusupov, R. M. 2004. Priural'e v epokhu velikogo pereseleniia narodov (Staro-Mushtinskii kurganno-gruntovyi mogil'nik) (Cis-Urals Area during the Great Migrations: Staraya Mushta Burial Ground). Ufa: "Ufimskii poligrafkombinat" Publ. (in Russian).

Tagirov, F. M 2007. In Ufimskii arkheologicheskii vestnik (Ufa Archaeological Herald) (6-7), 89-110 (in Russian).

Chernykh, E. M., Khairullina, O. F. 2018. In Arkheologiia Evraziiskikh stepei (Archaeology of Eurasian Steppes) 1, 86-106 (in Russian).

Kharpunov, N I. 2010. In Bosporskie issledovaniia (Bosporan Studies) 23, 459-462 (in Russian).

Sharov, O. V. 1992. In Shchukin, M. B., Gaj, O. A. (eds.). Problemy khronologii epokhi latena i rimskogo vremeni (Issues of Chronology of La Tène and Roman Period). Saint Petersburg: "Oium" Publ., 158-207 (in Russian).

Czarnecka, K. 1994. In Journal of Roman Military Equipment Studies. 5, 245-253.

James, S. 2004. The excavations at Dura-Europos conducted by Yale University and the French Academy of Inscriptions and Letters 1928 to 1937. Final Report VII. The Arms and Armour and other Military Equipment. London: The British Museum Press.

Kontny, B. 2016. In Rzeszotarska-Nowakiewicz., A. (ed.). In Past Societies. Vol. 4. Warszawa: Institute of Archaeology and Ethnology, Polish Academy of Sciences, 164-216 (in English).

Sim, D., Kaminski, J. 2012. Roman imperial armour: the production of early imperial military armour. Oxford: Oxbow Books.

Wijnhoven, M. A. 2018. In Sommer C. Sebastian, Matešic Suzana (eds.). In Limes XXIII: proceedings of the 23rd International Congress of Roman Frontier Studies Ingolstadt 2015. Mainz: Nünnerich-Asmus Verlag, 555-563.

\section{Abou the Author:}

Khairullina Olga F. Udmurt State University, Institute of History and Sociology. Universitetskaya St., 1 building 2, Izhevsk, 426034, Russian Federation; olenbka93@bk.ru 